\title{
Relationships between Brewer-Dobson circulation, double tropopauses, ozone and stratospheric water vapour
}

\author{
J. M. Castanheira ${ }^{1}$, T. R. Peevey ${ }^{2,3}$, C. A. F. Marques ${ }^{1}$, and M. A. Olsen ${ }^{4}$ \\ ${ }^{1}$ CESAM, Department of Physics, University of Aveiro, Portugal \\ ${ }^{2}$ National Center for Atmospheric Research, Boulder, Colorado, USA \\ ${ }^{3}$ Center for Limb Atmospheric Sounding, University of Colorado at Boulder, Boulder, Colorado, USA \\ ${ }^{4}$ Goddard Earth Sciences Technology and Research, Morgan State University, Baltimore, Maryland, USA
}

Correspondence to: J. M. Castanheira (jcast@ua.pt)

Received: 31 March 2012 - Published in Atmos. Chem. Phys. Discuss.: 15 May 2012

Revised: 24 October 2012 - Accepted: 29 October 2012 - Published: 6 November 2012

\begin{abstract}
Statistical relationships between the variability of the area covered by double tropopause events (DTs), the strength of the tropical upwelling, the total column ozone and of the lower stratospheric water vapour are analyzed. The QBO and ENSO signals in the double tropopause and tropical upwelling as well as their influence on the statistical relationships are also presented. The analysis is based on both reanalysed data (ERA-Interim) and satellite data.

Significant anticorrelations were found between the area covered by DTs and the total column ozone in the midlatitudes of the Northern Hemisphere. This relationship is confirmed by a large positive correlation between the areas covered by ozone laminae and double tropopause events as found in the HIRDLS satellite dataset. Significant anticorrelations were also found between the global area of double tropopause events and the near global $\left(50^{\circ} \mathrm{S}-50^{\circ} \mathrm{N}\right)$ water vapour in the lower stratosphere.

The correlations of DT variables with total column ozone and ozone laminae are both consistent with the poleward displacement of tropical air with lower ozone mixing ratio and with tropospheric intrusions of tropical tropospheric air into the lower extratropical stratosphere. The association of DTs with the poleward displacements of the tropical air is also consistent with a strong positive correlation between the area covered by DTs and the wave activity in the lower most stratosphere, between the first and second lapse rate tropopauses, as found in the ERA-Interim reanalysis.

Finally, a significant anticorrelation was found between the tropical upwelling and the near global lower stratospheric water vapour. Moreover, the step like decrease in the lower
\end{abstract}

stratospheric water vapour after 2001 is mirrored by a step like increase in the tropical upwelling.

\section{Introduction}

Stratospheric ozone accounts for about $90 \%$ of the total column ozone (TCO) and controls the amount of damaging UV radiation reaching the earth surface (Staehelin et al., 2001). The vertical profile of stratospheric ozone is also important for Earth's radiation budget, and thus climate change, since it absorbs both ultraviolet and terrestrial infrared radiation and an adjustment in the ozone distribution can change the mean temperatures of both the stratosphere and troposphere (McFarlane, 2008). Water vapour with its associated feedbacks is another radiative driver of the climate system. Recent research has highlighted this such as work by Solomon et al. (2010) that showed how stratospheric water vapour fluctuations may modulate the decadal global surface warming. The distribution and redistribution of these species in the stratosphere are controlled by a variety of mechanisms such as the Brewer-Dobson Circulation (BDC), quasi-horizontal mixing, and tropopause folds, to name a few. The distributions of both ozone and water vapour strongly impact the radiative heating field and stratospheric dynamics, which, in turn, has been shown to be important for long range weather forecasts and climate (e.g., Roff et al., 2011; Sigmond et al., 2008, and references therein).

In the lower and middle stratosphere, the BDC is forced mainly by the breaking of planetary-scale Rossby waves 
generated in the troposphere due to topography and landocean thermal contrasts (Holton et al., 1995). From the early fall to the late spring in each hemisphere chemical constituents are transported from the upper tropical troposphere to the extratropical lower stratosphere by the BDC. Water vapour enters the stratosphere through the tropical tropopause (Mote et al., 1996). It is then transported poleward by quasi-horizontal isentropic mixing, i.e., mixing along constant potential temperature surfaces, and the BDC. It is difficult to separate the contributions of these two transport processes because both the residual circulation and quasi-horizontal mixing are the result of wave breaking (Bönisch et al., 2011; Homeyer et al., 2011). However, a detailed understanding of the two contributions is required to assess how well Climate Models simulate stratospheric dynamics and tracer transport, and to increase the confidence in their projections.

Castanheira and Gimeno (2011) and Peevey et al. (2012) showed that double tropopause events (DTs) are associated with Rossby waves in the subtropics and midlatitudes. These waves can produce intrusions of tropical tropospheric air into the extratropical lower stratosphere (Randel et al., 2007; Pan et al., 2009). If these waves break they will contribute to the exchange of trace gases, such as ozone or water vapour, between the troposphere and the stratosphere through irreversible mixing (Pan et al., 2009). According Castanheira and Gimeno (2011) and Peevey et al. (2012) the variability in the frequency of double tropopause events should reflect the variability seen in the Rossby wave activity. Changes in this subtropical wave activity may ultimately be associated with changes in the tropical upwelling (Holton et al., 1995). Considering such possible links, it is reasonable to expect that the variability of double tropopause events will be related with the variabilities of the BDC strength and the mixing ratios of ozone and stratospheric water vapour.

Many studies have analyzed the relationships between the $\mathrm{BDC}$, ozone and stratospheric water vapour, and the effects of the QBO on those relationships (see, for example, Baldwin et al., 2001; Fujiwara et al., 2010; Randel, 2010; Bönisch et al., 2011, and refereces therein). In this study we reassess those relationships and introduce a new variable: the occurrence of double tropopause events. Our main goal is to explain how horizontal advection and quasi-horizontal mixing associated with DTs can impact the variability of ozone and stratospheric water vapour, and the dynamical relationship between DTs and the ascending branch of the BDC at the tropical tropopause level.

\section{Data and method}

\subsection{Satellite and reanalysis data}

The present study is based on ERA Interim (ERA-I) reanalysis data (Dee et al., 2011) on isobaric levels at 00:00 and
12:00 UT from 1979 to 2010, on total column ozone (TCO) observed from three satellite instruments (Earth Probe, Nimbus 7 and OMI), and on water vapour data from the Halogen Occultation Experiment (HALOE) and Aura Microwave Limb Sounder (MLS). The water vapour data were kindly made available by William Randel and are the same as used in Randel (2010). An independent assessment of the relationship between ozone and DTs was done using observations from the High Resolution Dynamics Limb Sounder (HIRDLS) satellite instrument.

Nimbus 7 and Earth Probe TCO data were downloaded from the TOMS web page (http://toms.gsfc.nasa.gov/ozone) and were analyzed for the periods January 1979 to December 1992 and August 1996 to November 2005, respectively. OMI ozone data (level 3, version 8) were downloaded from ftp://toms.gsfc.nasa.gov/pub/omi/data/ and cover the period from October 2004 to December 2010. Satellite data from HALOE covering January 1992 to August 2005 (version v19) were combined with Aura MLS for the period June 2004 to May 2010 (v2.2), to produce a single time series by adjusting the data using the overlap period during 2004-2005 (see Randel, 2010 for more details). HIRDLS data (level 2, version 5) were available from January 2005 to December 2007. An overview of both the HIRDLS temperature and ozone products, along with further references contained within, is available from Gille and Gray (2010).

\subsection{Fraction of area covered with DTs}

The first and, if present, second thermal lapse rate tropopauses were identified using the conventional WMO (1957) criteria:

a. The first tropopause is defined as the lowest level at which the lapse rate decreases to $2 \mathrm{~K} \mathrm{~km}^{-1}$ or less, provided also that the average lapse rate between this level and all higher levels within $2 \mathrm{~km}$ does not exceed $2 \mathrm{Kkm}^{-1}$.

b. If above the first tropopause the average lapse rate between any level and all higher levels within $1 \mathrm{~km}$ exceeds $3 \mathrm{~K} \mathrm{~km}^{-1}$ then a second tropopause is defined by the same criterion as in (a). This tropopause may be either within or above the $1 \mathrm{~km}$ layer.

Because of the low $(\sim 1 \mathrm{~km})$ vertical resolution in the UTLS, condition (b) in the above definition was reduced to $2.5 \mathrm{~K} \mathrm{~km}^{-1}$ when analyzing the ERA-I data. A similar procedure was applied by Randel et al. (2007), who reduced condition (b) to $2 \mathrm{~K} \mathrm{~km}^{-1}$ in their analysis of the ERA40 data. The criteria used to find the tropopauses were applied using an algorithm that is similar to that used by Birner (2010) (which in turn is a slight variation of the algorithm used by Reichler et al., 2003).

For each reanalysis time, $t_{i}$, we calculated the fraction of area $\left(\mathrm{FA}_{\mathrm{NH}}\right)$ of the latitudinal band $20-65^{\circ} \mathrm{N}$, where double 
tropopause (DT) events occur, using the following equation:

$\mathrm{FA}_{\mathrm{NH}}\left(t_{i}\right)=\frac{\sum_{n^{*}}^{N^{*}\left(t_{i}\right)} \cos \left(\varphi_{n^{*}}\left(t_{i}\right)\right)}{\sum_{n}^{N} \cos \left(\varphi_{n}\right)} \times 100$,

where $N$ is the number of grid points in latitudinal band 20$65^{\circ} \mathrm{N}$, and $N^{*}\left(t_{i}\right)$ is the number grid points inside that latitudinal band where DTs were identified at time $t_{i} ; \varphi_{n^{*}}\left(t_{i}\right)$ are the latitudes of grid points where DTs were identified.

A similar time series, $\mathrm{FA}_{\mathrm{SH}}$, was obtained for the latitudinal band $20-65^{\circ} \mathrm{S}$. The mean of the two time series $\left[\mathrm{FA}=\left(\mathrm{FA}_{\mathrm{NH}}+\mathrm{FA}_{\mathrm{SH}}\right) / 2\right]$ represents the fraction of area of the two latitudinal bands where DTs occur.

\subsection{Anomaly time series}

Ozone and water vapour were available as (calendar) monthly means. Other variables with hourly resolution were averaged into calendar monthly means. The seasonal cycle of each variable was removed by subtracting the interannual monthly mean from each month. The anomalies were then smoothed by a 5-month running mean. Because of the short length of the ozone time series from the Earth Probe and OMI instruments, all time series analyzed in conjunction with either of those two instruments were smoothed by a 3-month running mean to maintain an adequate number of statistical degrees of freedom. The treatment of the HIRDLS data will be explained in the next section.

Figure 1 shows a 5-month running average of the FA anomalies. The figure also shows the multilinear regression of the FA anomalies onto the time series of the QBO, ENSO and solar cycle. The QBO is represented by the monthly mean of the equatorial zonal mean zonal wind at 30 and $70 \mathrm{hPa}$ (U30 and U70, respectively). These two time series are nearly orthogonal (their correlation is $r=-0.08$ ), and allow the strength and phase of the QBO to be accounted for. The ENSO is represented by the Multivariate ENSO Index (MEI) that was obtained from the NOAA web site (http://www.esrl.noaa.gov/psd/enso/mei/). The solar cycle is represented by the adjusted time series of the solar $10.7 \mathrm{~cm}$ flux observed in Penticton, British Columbia, available at http://www.ngdc.noaa.gov/stp/solar/flux.html. All indices are available as (calendar) monthly means and were smoothed using a 5-month running average before the multilinear regression was applied. The area associated with DT events does not show a correlation $(r=-0.05)$ with the solar cycle, whereas its correlation values with the ENSO index and the QBO are $r=-0.40$ and $|r|=0.50$, respectively. The multilinear regression coefficients show that DTs events are more frequent during the easterly phase of the QBO at $70 \mathrm{hPa}$. Because the relationships between BDC, double tropopauses, ozone and stratospheric water vapour may be sensitive to the phases of ENSO and the QBO, we performed the calculations for both the total data anomalies and for the time series with the signals of the QBO, ENSO and solar cycle removed using a multilinear regression.

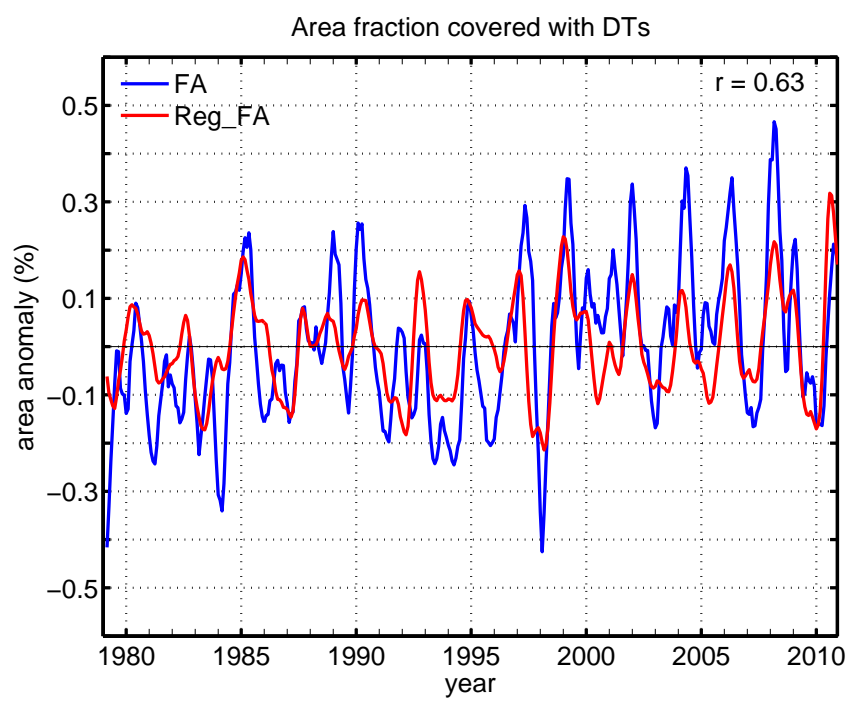

Fig. 1. The blue curve represents the monthly anomalies of the fraction of area (FA) associated with DTs within the $20-65^{\circ} \mathrm{N}$ and $20-65^{\circ} \mathrm{S}$ latitude bands. The red curve represents the multilinear regression of the FA anomalies onto the time series of the QBO, ENSO and solar cycle. Both curves were smoothed by a 5-month running average. The correlation between the two time series is $r=0.63$.

The statistical significance of correlations between time series, which were smoothed by a 5-month running mean and by a 3-month running mean, were assessed adopting the conservative assumption that only 2 and 3 degrees of freedom per year remained after the smoothing, respectively. A twosided parametric $\mathrm{t}$-test was considered for all cases.

\section{Results}

\subsection{DTs versus Rossby wave activity}

As already mentioned, Castanheira and Gimeno (2011) and Peevey et al. (2012) showed that double tropopause events (DTs) are associated with Rossby waves in the subtropics and midlatitudes. This association is analyzed here by calculating the correlation between the monthly mean anomalies of the area covered with DTs in the $\mathrm{NH}\left(\mathrm{FA}_{\mathrm{NH}}\right)$ and the monthly mean anomalies of the area weighted average of the quasi-geostrophic wave activity in the latitudinal band $30-50^{\circ} \mathrm{N}$. The wave activity, $A$, was calculated by (Andrews et al., 1987, chapter 3)

$A=\frac{1}{2} \frac{\rho_{0} \overline{q^{\prime 2}}}{\frac{1}{a} \frac{\partial \bar{q}}{\partial \varphi}}$,

where $\rho_{0}(z)=\rho_{s} e^{-z / H}$ is the reference density; $z$ is the logpressure altitude; $\bar{q}$ are the zonal mean quasi-geostrophic potential vorticity and $q^{\prime}$ is its deviation from the zonal 
mean; $\varphi$ is the latitude; and $a$ is the earth radius. The quasigeostrophic potencial vorticity is given by

$q=f+\frac{1}{f_{0}} \nabla^{2} \Phi+\frac{f_{0}}{\rho_{0}} \frac{\partial}{\partial z}\left(\frac{\rho_{0}}{N_{0}^{2}} \frac{\partial \Phi}{\partial z}\right)$,

where $\Phi$ is the geopotential deviation from the isobaric mean in the latitudinal band $30-60^{\circ} \mathrm{N}, f$ is the Coriolis parameter $\left(f_{0}=2 \Omega \sin \left(45^{\circ}\right)\right)$, and $N_{0}^{2}$ is the stability parameter

$N_{0}^{2}=\frac{R}{H}\left(\frac{\mathrm{d} T_{0}}{\mathrm{~d} z}+\frac{\kappa T_{0}}{H}\right)$,

The variable $T_{0}$ is the basic state reference temperature which depends only on pressure; $R$ is the specific gas constant of dry air; $H$ is a mean scale height; and $\kappa=R / c_{p}$, where $c_{p}$ is the specific heat of air at constant pressure.

In the limits of the linear approximation, wave activity is proportional to the zonal variance of the Lagrangian meridional displacements, $\eta^{\prime}$, of the atmospheric particles (see for example, Andrews et al., 1987, eq. 3.6.10)

$A=\frac{\rho_{0}}{2 a} \frac{\partial \bar{q}}{\partial \varphi} \overline{\eta^{\prime 2}}$.

This relationship between wave activity and the meridional displacements, $\eta^{\prime}$, of atmospheric particles and the interpretation of DTs as the result of a meridional overlap of the tropical and extratropical tropopauses is a clear reason to expect a relationship between wave activity and DTs. The proportionality constant between wave activity and the zonal variance, $\overline{\eta^{\prime 2}}$, of the meridional displacements of atmospheric particles is $\left(\rho_{0} / 2 a\right) \partial \bar{q} / \partial \varphi$. Therefore, in order to make the monthly wave activity comparable between different years, we used the calendar monthly climatologies of $\partial \bar{q} / \partial \varphi$ in Eq. (2).

The association between DTs and Rossby waves found in this study is highlighted in Fig. 2. Correlations in this Figure were calculated using calendar month anomalies without smoothing using a moving average. The blue curve represents the correlation using all months, and the red curve gives the correlation for the winter (November-March) months. Both curves show clear peaks in the region between the first and second lapse rate tropopauses, demonstrating an association between Rossby wave activity and the frequency of DTs.

\subsection{Ozone versus DTs}

Randel et al. (2007), Pan et al. (2009) and Castanheira and Gimeno (2011) showed observational evidence that double tropopause structures could result from excursions of the tropical tropopause and tropical air over the extratropical tropopause. In general, ozone mixing ratios in the lower most stratosphere (LMS) increase from the tropics to extratropics so large positive anomalies in the area associated with DTs should be associated with negative anomalies of the zonal

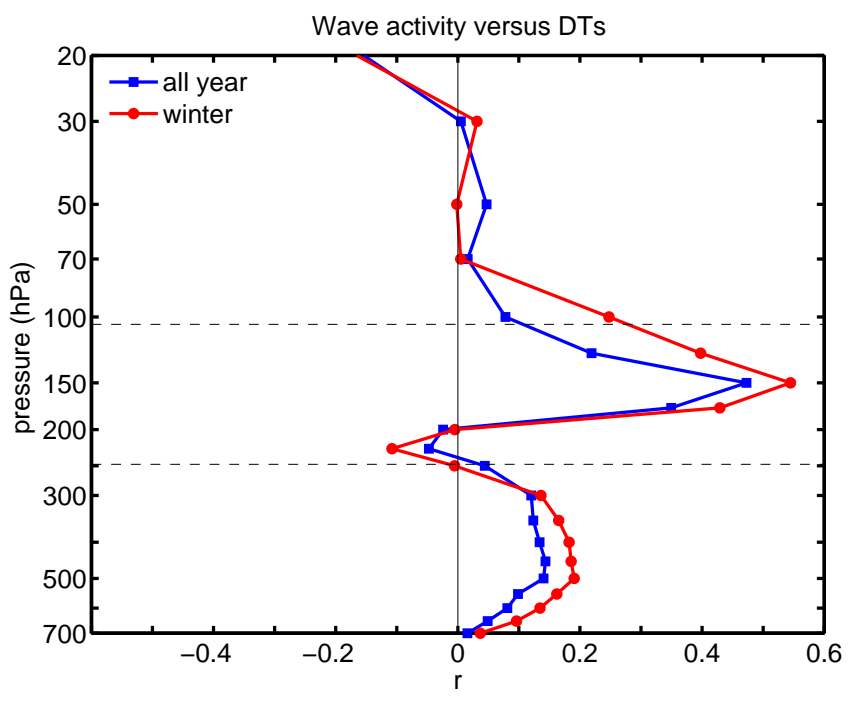

Fig. 2. Correlation between the area covered with DTs in the NH and the area weighted average of the quasi-geostrophic wave activity, $A$, in the latitudinal band $30-50^{\circ} \mathrm{N}$. The blue curve represents the correlations considering all months, and the red curve represents the correlations for the winter (November-March) months. The horizontal dashed lines mark the mean log pressure height of the first and second lapse rate tropopauses in the latitudinal band $30-50^{\circ} \mathrm{N}$.

mean ozone in the lower extratropical stratosphere. Because much of TCO is concentrated in the lower stratosphere (Staehelin et al., 2001), we expect the signal of DTs also to be detectable in the total ozone.

Castanheira and Gimeno (2011) and Peevey et al. (2012) showed that the variability of the meridional extension of the tropical tropopause over the extratropical tropopause, and therefore the variability of the area where DTs occur, is associated with Rossby wave variability. That association between DTs and Rossby wave activity was also demonstrated in the above subsection.

Waves associated with DT events may be reversible, with tropical air moving to the extratropics and returning back the tropics without mixing into the midlatitudes (Olsen et al., 2010). A higher correlation between the fractional area of DTs and the TCO is expected, if we define the ozone time series using the weighted area average of TCO, in the extratropical latitudinal band where the occurrence of DTs is more frequent. Figure 1 of Castanheira and Gimeno (2011) shows that the maximum frequency of DT events occurs in the latitudinal band $30-45^{\circ} \mathrm{N}$. Although, Fig. 1 of Castanheira and Gimeno (2011) shows results during NH winter, a similar result is obtained considering the full year. Therefore, ozone time series were constructed using the area weighted averages of column ozone anomalies within the previously mentioned latitudinal band $\left(30-45^{\circ} \mathrm{N}\right)$. Figure 3 shows a scatter plot of the mean ozone anomalies as a function of area anomaly of DTs in the $\mathrm{NH}\left(\mathrm{FA}_{\mathrm{NH}}\right)$. The plot shows significant anticorrelation between the anomalies of TCO and the 


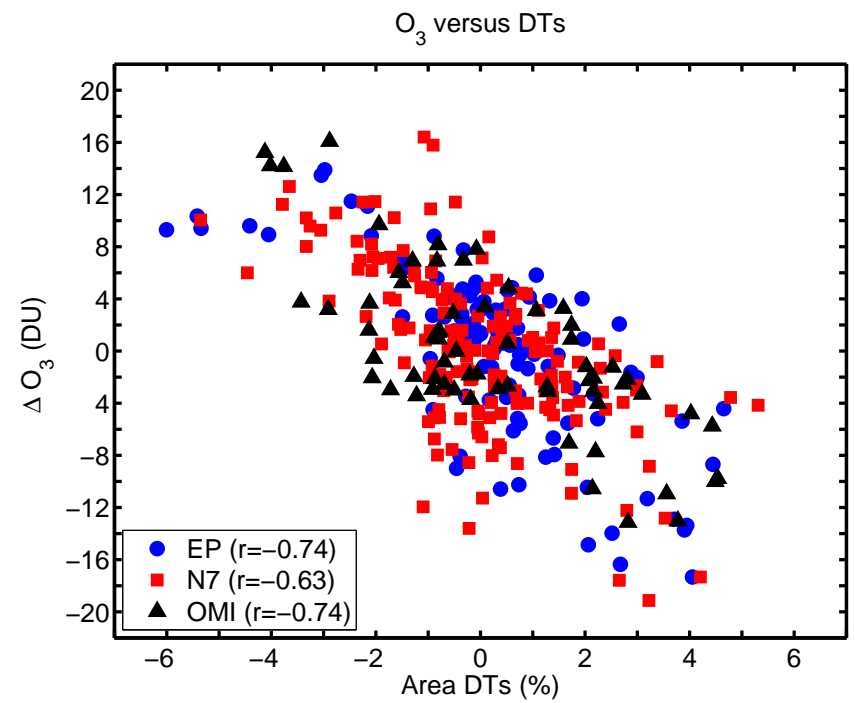

Fig. 3. Anomalies of column ozone in the $30-45^{\circ} \mathrm{N}$ latitude band as a function of the anomalies of the fraction of area $\left(\mathrm{FA}_{\mathrm{NH}}\right)$ associated with DTs in the NH. Ozone data were derived from three satellite platforms: Earth Probe (EP), Nimbus 7 (N7) and OMI. Using the conservative assumption that there are only three degrees of freedom per year and for a two-sided t-test, the correlation for OMI data is statistically significante at the $95 \%$ level, and the correlations for Earth Probe and Nimbus 7 data are statistically significant at the $99 \%$ level.

area of DTs. The correlations values are $r=-0.74,-0.63$ and -0.74 for the ozone data derived from the Earth Probe, Nimbus 7 and OMI satellites instruments, respectively. Figure 4 shows a similar plot but for the ozone column from the ERA-I reanalysis (1979-2010). The correlation value is $r=-0.64$. In order to reduce the possible effects associated with chemical ozone depletion, the time series of Nimbus 7 (1979-1992) was linearly detrended, and a 5-yr running mean was removed from the ozone series derived from the ERA-I reanalysis. The correlation for OMI data is statistically significant at the $95 \%$ level, and the correlations for Earth Probe, Nimbus 7 and ERA-I data are statistically significant above the $99 \%$ level.

Because the ERA-I TCO data are available for a longer period (1979-2010) than those from satellite instruments, we calculated also the correlation between the ERA-I TCO and the area covered by DTs in the $\mathrm{NH}\left(\mathrm{FA}_{\mathrm{NH}}\right)$ after removing the variabilities associated with the QBO, ENSO and solar cycle from both TCO and DTs time series. Variability associated with the QBO, ENSO and solar cycle was obtained using a multilinear regression. The correlation value between the ERA-I TCO and DTs residual time series is $r=-0.59$ and is statistically significant above the $99 \%$ level $(p=0.01)$. This result suggests that the ozone anomalies associated with the DTs anomalies are intrinsic to the DTs variability and not imposed by the co-variability with the QBO or the solar cycle. Because the effects of the QBO and solar cycle has

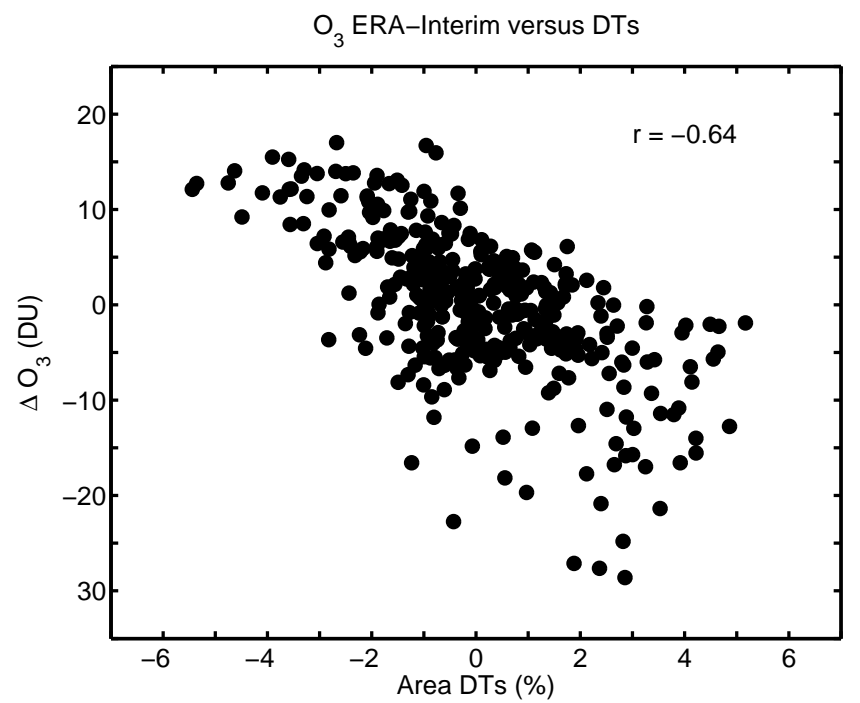

Fig. 4. As in Fig. 3 but with column ozone from ERA Interim reanalysis (1979-2010). A 5-yr running mean was removed from both time series. The correlation is statistical significant at the $99 \%$ level (see the text).

been assessed only in the ERA-I data, it is worth to note that the TCO of ERA-I compares quite well with observational data, at least for averaged values between $50^{\circ} \mathrm{S}$ and $50^{\circ} \mathrm{N}$ (Dragani, 2011).

The relationship between ozone and DTs was tested independently by using variables derived from the HIRDLS instrument data for the period 2005-2007. The analysed variables were the areas associated with ozone laminae and DTs in the NH. Ozone laminae are identified following the method of Olsen et al. (2010). However, we do not restrict the lamina thickness nor require continuity across adjacent profiles as originally presented by Olsen et al. (2010). In addition, the vertical range is expanded, spanning $340 \mathrm{~K}$ to $550 \mathrm{~K}$ on $5 \mathrm{~K}$ increment potential temperature surfaces. For consistency with the method of ozone laminae identification, HIRDLS temperature profiles were averaged within 2 degree latitude bins between $22-72^{\circ} \mathrm{N}$, and the DTs were identified as in Peevey et al. (2012). Next, two daily time series representing the areas of DTs and ozone laminae were calculated. The areas of each ozone lamina profile and each DT profile are represented by the cosines of the latitude of bins where they are found. Daily time series for both the areas of the laminae and DTs were then calculated by a sum of the cosines of the latitudes of all bins where laminae or DTs were found each day. During this process two restrictions were implemented: (1) the second tropopause must be between $70 \mathrm{hPa}$ and $150 \mathrm{hPa}$ and (2) the potential temperature of the ozone minimum is below the maximum potential temperature of the restricted second tropopause or below $400 \mathrm{~K}$ if no second tropopause is present. This helps to ensure that both the DT and ozone lamina are characteristic 


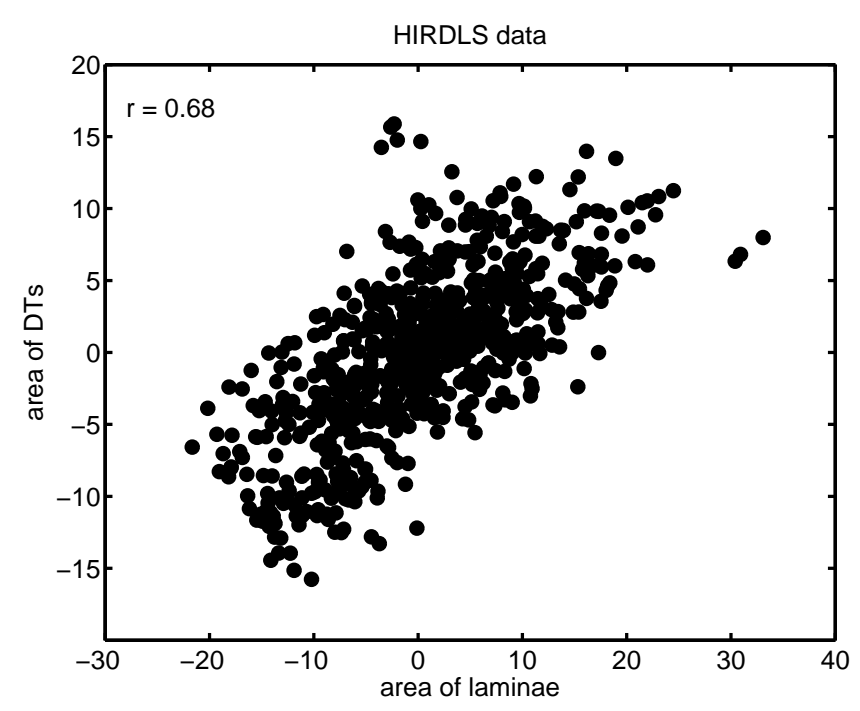

Fig. 5. Correlation between the area covered with DTs and the area covered with ozone laminae in the latitude band $22-72^{\circ} \mathrm{N}$ as observed by the HIRDLS satellite instruments. Only November to June anomalies are plotted. The correlation is statistically significant at the $99 \%$ level (see text).

of tropospheric intrusions. We deseasonalize the time series by first finding the average areas of DTs and ozone laminae for each day of the year and smoothing using a 29-day moving average. That time series, which represents the seasonal cycle, is removed from the original data. This is done for both the DT and ozone lamina area time series. The anomaly time series were then smoothed by a 5-day running mean. Additionally, because both DT and ozone laminae frequency are small during the summer (Olsen et al., 2010; Peevey et al., 2012), only anomalies between November and June were analyzed. As seen in Fig. 5, there is a strong correlation between the area of DTs and the area of ozone laminae. This is consistent with negative anomalies of TCO associated with positive anomalies in the area of DTs due to both the northward displacement of lower stratospheric tropical air with low ozone mixing ratio and tropospheric intrusions of tropical tropospheric air into the lower extratropical stratosphere. Again, using a conservative assumption that there are only three degrees of freedom per month and a two-sided test, the correlation between ozone laminae and DTs is statistically significant above the $99 \%$ level. Because the HIRDLS data are available for the 3-yr period 2005-2007, only a crude estimate of the seasonal cycle can be made. However, calculating the correlations for each month separately and then averaging gives qualitatively similar results.

\subsection{Lower stratospheric water vapour versus DTs}

If waves associated with the tropopausal overlap have large amplitudes they could break, resulting in the mixing of tropical and extratropical air (Pan et al., 2009) and contributing to the exchange of trace gases, e.g., water vapour, between the tropics and extratropics. Bönisch et al. (2011) suggested that the stratospheric water vapour drop after 2001 was a consequence of an enhanced quasi-horizontal (isentropic) mixing accompanied by an intensification of the residual circulation in the lower most stratosphere (LMS).

Considering the above results and assuming that large anomalies in the FA time series for DTs may be associated with quasi-horizontal mixing events in the LMS, we analyzed the correlation between FA and the mixing ratio of water vapour on isobaric levels. A step like decrease of water vapour in the lower stratosphere after 2001 has been observed in instrument data (e.g., Randel et al., 2006; Randel, 2010). Because the relationships between water vapour, DTs and tropical upwelling must be observable on the interseasonal and interannual time scales, we removed the signal of the 2001 water vapour drop as follows. For the HALOE-Aura MLS instruments the periods November 1991 to December 2000 and January 2001 to May 2010 were subtracted by their respective means before beginning an analysis of correlations. In the case of the longer time series from ERA-I the interdecadal variability was removed by subtracting a ten year (121 months) moving average. Hereafter, unless otherwise explicitly mentioned, only interseasonal and interannual variability will be analyzed. Additionally the QBO, ENSO and solar flux signals were always computed using the original anomaly time series.

Figure 6 shows lagged correlations between the FA time series and the water vapour time series derived using near global $\left(50^{\circ} \mathrm{S}-50^{\circ} \mathrm{N}\right)$ water vapour data from the HALOE and Aura MLS instruments. Figure 7 shows the same kind of correlations but with water vapour from ERA-I reanalysis. The correlation patterns show the typical "tape-recorder" signal of the BDC, which is apparently stronger in the ERA-I reanalysis than in the observations, as was already noted by Dee et al. (2011). Additionally, the left panels in both figures show a clear QBO signal. The right panels show the correlations between the residual variability, i.e., with the variability associated with the QBO, ENSO and solar cycle removed from the original time series using a multilinear regression, of the two time series. Statistical significant (above the $95 \%$ level) anticorrelations near the zero lag (Right panels in Figs. 6 and 7) remain after removing the signal of the QBO and the ENSO, which suggests that at least part of the correlation between the DT and water vapour anomalies is inherent to the mechanism producing the DTs. High anticorrelations between $\sim 150$ - and $\sim 100$-hPa isobaric levels, where the patterns show a vertical elongation, may partially be due to subsidence of the first tropopause associated with DT events (Añel et al., 2008; Peevey et al., 2012). Because the water vapour mixing ratio drops very rapidly through the tropopause layer, subsidence of the first tropopause will induce large negative anomalies in the water vapour mixing ratio at fixed isobaric level near the tropopause. Moreover, the nearly vertical orientation of the correlation pattern is 


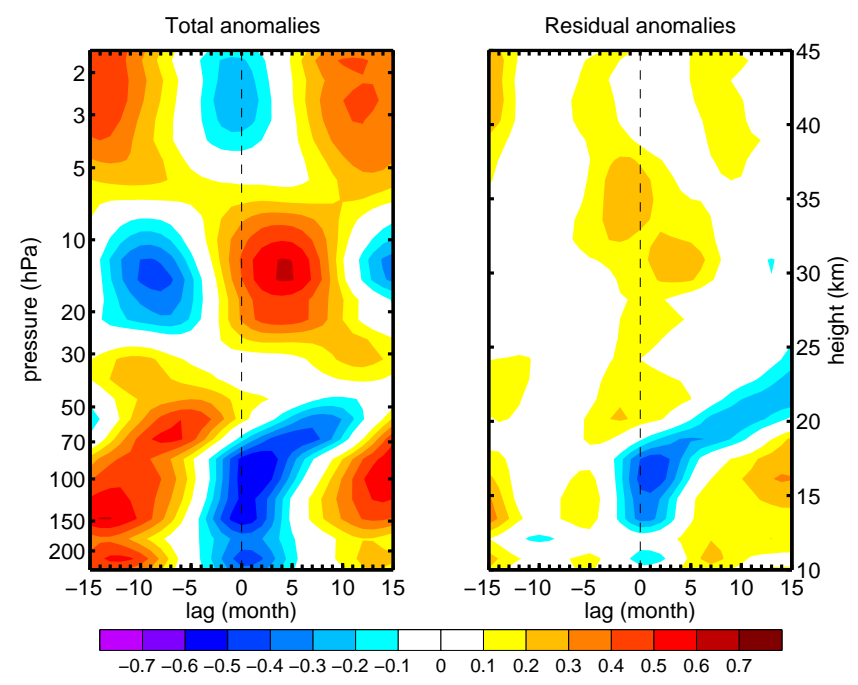

Fig. 6. Lagged correlations between the area covered with DTs, i.e., the time series FA, and the area weighted mean of specific humidity in the latitudinal band $50^{\circ} \mathrm{S}-50^{\circ} \mathrm{N}$ derived from the HALOE and Aura MLS instruments. The right panel shows the correlations between the two time series after the QBO, ENSO and solar cycle signals have been removed by a multilinear regression. Absolute correlation values greater than 0.3 are statistically significant above the $95 \%$ level (see text). Positive lags mean that DTs are leading.

also consistent with a higher vertical residual velocity in the $16-18 \mathrm{~km}$ layer, as shown by the results of Schoeberl et al. (2010).

The left panels of Figs. 6 and 7 (see also Figs. 9 and 10) show three vertical layers with distinct phase relationships to the QBO. These correlation patterns must be associated with the vertical amplitude modulation of the water vapour anomalies by the residual circulation associated with the downward progression of the QBO (e.g., Randel et al., 1998, Fig. 21). The same kind of modulation is also observed in both the ozone (e.g., Baldwin et al., 2001, Fig. 22) and temperature anomalies (Huang et al., 2008).

\subsection{Tropical upwelling versus water vapour and DTs}

The main sources of stratospheric water vapour are methane oxidation and transport from the troposphere through the tropical tropopause. This implies that variability and trends in the stratospheric water vapour field may be caused by two things, (1) changes in the fraction of oxidised methane (Le Texier et al., 1988) and (2) changes in the entry mixing ratios of methane and water vapour as well as by their transport associated with the diabatic meridional circulation, i.e., the Brewer-Dobson circulation, and the irreversible quasihorizontal mixing (Mote et al., 1996). In this subsection, the variability of the near global lower stratospheric water vapour will be related to the variability in upwelling through the tropical tropopause which is placed near $100 \mathrm{hPa}$.

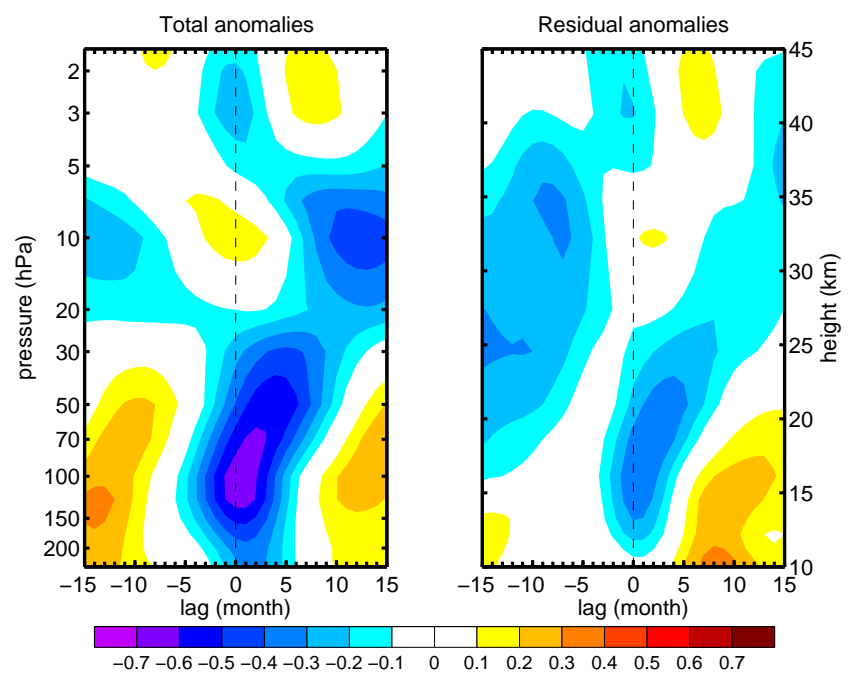

Fig. 7. As in Fig. 6 but using water vapour from the ERA-I reanalysis for the period 1979-2010. Absolute correlation values greater than 0.3 are statistically significant above the $99 \%$ level (see text).

The ERA-I mean residual vertical velocity, $\left\langle\bar{w}^{*}\right\rangle$, in the tropical region bounded by the latitudes $-\varphi_{0}$ and $\varphi_{0}$, was computed using the downward control principle as in Randel et al. (2002)

$$
\begin{aligned}
& \left\langle\bar{w}^{*}\right\rangle(z)=\frac{1}{2 \rho_{0}(z) \sin \varphi_{0}} \\
& \left\{\int_{z}^{\infty}\left[\cos \varphi \frac{\nabla \cdot \mathbf{F}-\rho_{0}\left(z^{\prime}\right) \partial \bar{m} / \partial t}{\partial \bar{m} / \partial \varphi}\right]_{\bar{m}} \mathrm{~d} z^{\prime}\right\}_{-\varphi_{0}}^{\varphi_{0}},
\end{aligned}
$$

where $\mathbf{F}$ is the Eliassen-Palm (E-P) flux, $\bar{m}=$ $a \cos \varphi(\bar{u}+a \Omega \cos \varphi)$ is the zonal mean absolute angular momentum. All variables were defined as in Sect. 3.5 of Andrews et al. (1987), and the subscript $\bar{m}$ means that the integral was evaluated along contours of constant angular momentum, $\bar{m}(\varphi, z)$. In this study, the residual velocity was calculated at the log pressure altitude of the $100 \mathrm{hPa}$ level.

In the remaining analysis, results will be shown for the mean residual vertical velocity within the tropical band $22.5^{\circ} \mathrm{S}-22.5^{\circ} \mathrm{N}$. For wider tropical bands the results remain qualitatively the same. On the other hand, for smaller latitude limits, the calculation of the integral along contours of constant $\bar{m}(\varphi, z)$ is problematic because the condition $\partial \bar{m} / \partial \varphi \neq 0$ is violated a large number of times.

\subsubsection{Tropical upwelling versus DTs and QBO}

The residual velocity is forced by the divergence of the E-P flux, which, in the linear quasi-geostrophic approximation, is proportional to wave activity. Because of this relationship and the association of double tropopauses with Rossby wave activity, it is reasonable to expect a relationship between the residual velocity in the lower stratosphere and the area 

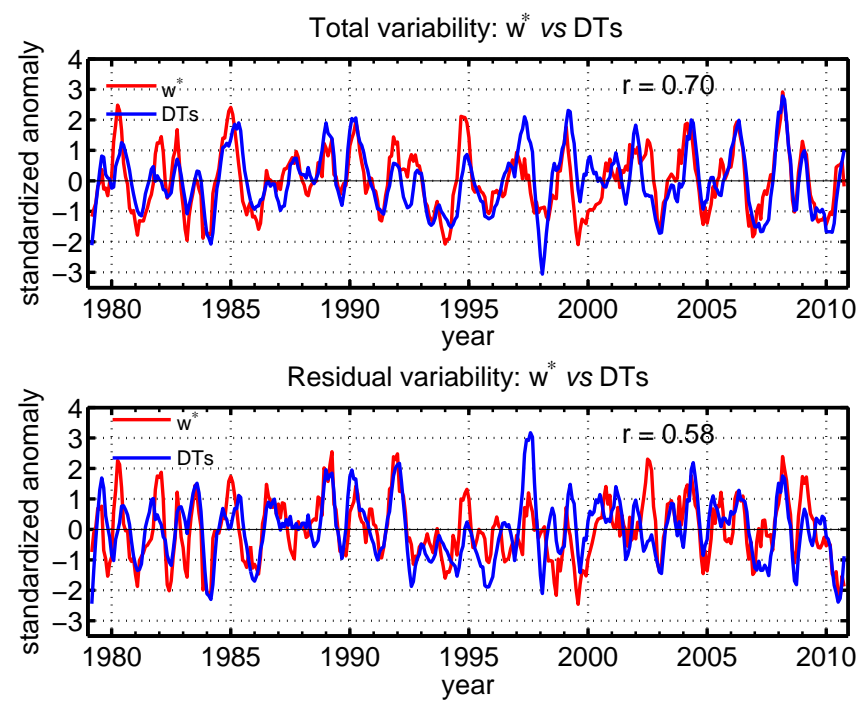

Fig. 8. Time series of the mean residual vertical velocity, $\left\langle w^{*}\right.$, in the tropics $\left(22.5^{\circ} \mathrm{S}-22.5^{\circ} \mathrm{N}\right)$ and of the fraction of area covered with DTs (FA) derived from ERA-I reanalysis. Both time series were smoothed by a 5-month running mean and normalized by their respective standard deviations. The bottom panel shows the correlations between the two time series after the QBO, ENSO and solar cycle signals have been removed from the original anomaly time series by a multilinear regression.

covered by double tropopauses. As seen in Fig. 8, a strong linear relationship exists between DTs and the vertical residual velocity at the tropopause level. Moreover, the curves in the lower panel of Fig. 8 show that the relationship between DTs and the vertical residual velocity is intrinsic to them and not due to "external" factors like the QBO, the ENSO or the solar cycle.

Correlation calculations between the residual velocity and the QBO, the ENSO and the solar flux showed that there is no significant correlation between the ENSO and $\left\langle\bar{w}^{*}\right\rangle$ $(r=-0.19)$ and no significant correlation between the solar flux and $\left\langle\bar{w}^{*}\right\rangle(r=-0.03)$. On the other hand, there is a strong correlation $(|r|=0.63)$ between the QBO and $\left\langle\bar{w}^{*}\right\rangle$. As referred in the data section, the time series of the equatorial zonal mean zonal wind at 30 and $70 \mathrm{hPa}$ (U30 and U70, respectively), used to represent the QBO, are nearly orthogonal. The single correlations of $\left\langle\bar{w}^{*}\right\rangle$ with $\mathrm{U} 30$ and $\mathrm{U} 70$ are $r=0.05$ and $r=-0.63$, respectively. These results indicate that, in the mean, the residual velocity is stronger during the easterly phase of the QBO at $70 \mathrm{hPa}$. Moreover, the correlation between U70 and the vertical shear of the equatorial zonal mean wind, $\partial \bar{u} / \partial z$, is positive in the LMS, with a value of $r=0.79$ at the $100 \mathrm{hPa}$ isobaric level. This means that the easterly U70 is associated with easterly zonal mean wind shear in the LMS. Therefore the value found for the correlation between U70 and $\left\langle\bar{w}^{*}\right\rangle$ is consistent with the theoretical results using two-dimensional models of the QBO (Baldwin et al., 2001, and references therein). According to

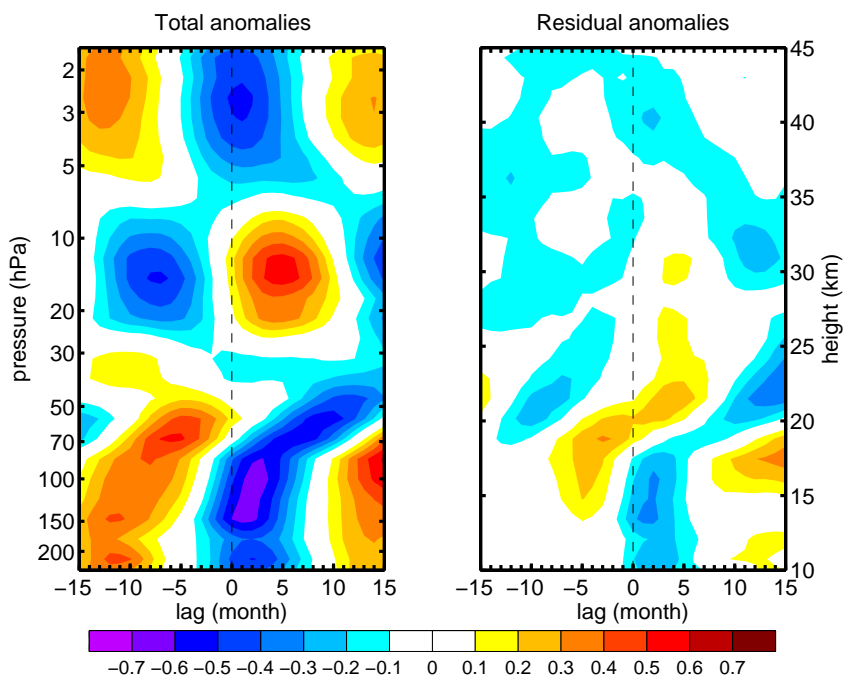

Fig. 9. Lagged correlations between the tropical upwelling and the area weighted mean of the water vapour mixing ratio within the latitudinal band $50^{\circ} \mathrm{S}-50^{\circ} \mathrm{N}$ derived from the HALOE and Aura MLS instruments. Both time series were smoothed by a 5-month running mean. The right panel shows the correlations between the two time series after the QBO, ENSO and solar cycle signals have been removed from the original anomaly time series by a multilinear regression. Positive lags mean that $\left.\overline{\left\langle w^{*}\right.}\right\rangle$ is leading.

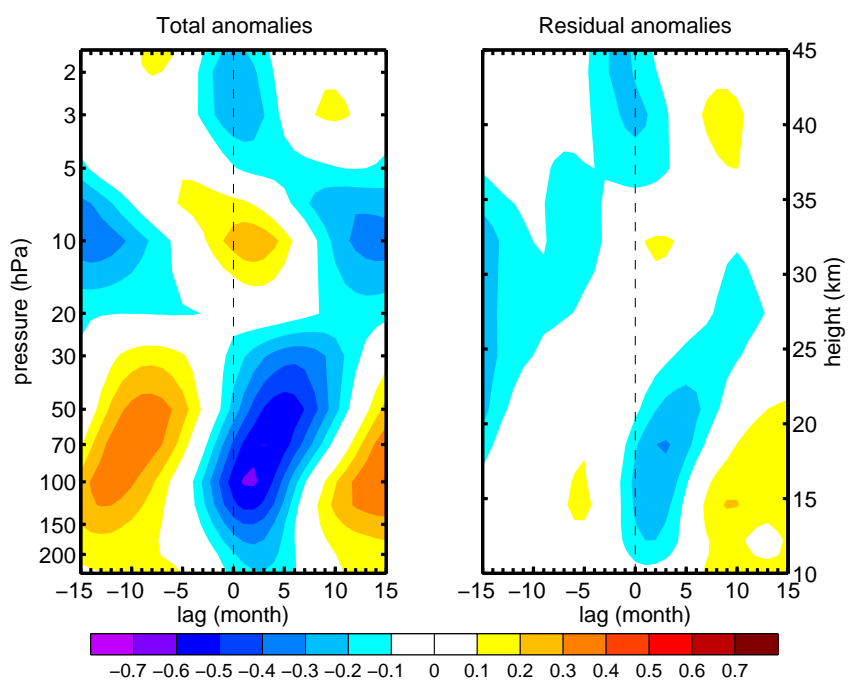

Fig. 10. As in Fig. 9 but with the area weighted mean of of ERA-I specific humidity in the latitudinal band $50^{\circ} \mathrm{S}-50^{\circ} \mathrm{N}$.

those models, westerly shear zones of the QBO are associated with sinking anomalies of the residual circulation at the equator, whereas the easterly shear zones are associated with rising anomalies.

\subsubsection{Tropical upwelling versus water vapour}

As shown in Sect. 3.3, the signal in the correlation pattern found for water vapour and DTs anomalies is propagated 


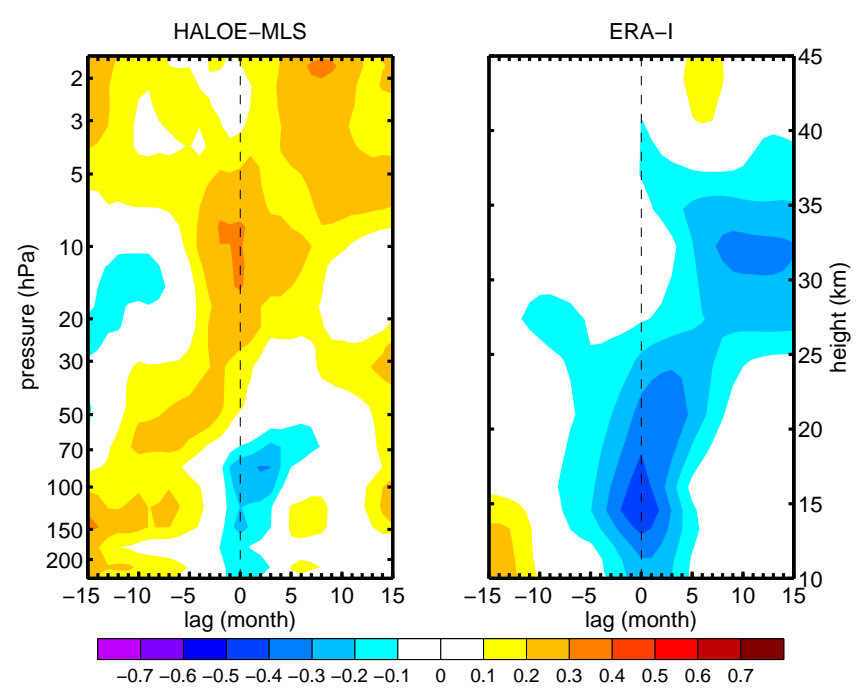

Fig. 11. Lagged correlations between the area covered with DTs and the area weighted mean of the water vapour mixing ratio within the latitudinal band $50^{\circ} \mathrm{S}-50^{\circ} \mathrm{N}$ derived from the HALOE and Aura MLS instruments (left) and ERA-I reanalysis (right). Both panels show the correlations between the respective time series after subtracting the variabilities regressed upon the tropical upwelling time series.

upwards in the lower stratosphere by the residual circulation. On the other hand, the anomalies of the residual vertical velocity at the tropopause level are positively correlated with the DTs anomalies. Therefore, it is important to assess the contribution of the tropical upwelling variability to the correlation signal found between the DTs and the lower stratospheric water vapour.

Figures 9 and 10 show lagged correlations between the residual vertical velocity, at $100 \mathrm{hPa}$, and the near global water vapour. The correlation patterns are quite similar to the respective correlation patterns obtained for the DTs (Figs. 6 and 7). The large correlation between the tropical upwelling and the fraction of area covered with DTs (Fig. 8), and the large correlation between tropical upwelling and water vapour may indicate that much of the water vapour and DTs correlated variabilities are also covariant with the tropical upwelling. The correlations in Fig. 11 show that such an association is in fact true. The correlations between the DT and water vapour time series, in the lower stratosphere, are strongly reduced when we subtract the variability regressed on the tropical upwelling time series. This result shows that it is difficult untangle the effects due to the transport by the residual circulation and to the quasi-horizontal motion in the observed data (Bönisch et al., 2011).

The right panel of Fig. 11 shows that statistical significant correlation ( $r \geq 0.3$ for $p=0.01)$ in the ERA-I data remains after removing the variability associated with the tropical upwelling. Although, the ERA-I water vapour analysis at stratospheric levels has very little influence from observa- tions being mostly a model field product (Dee et al., 2011), they reproduce well the minimum specific humidity in the lower most stratosphere in the tropics as seen in the observations (see, for example, Figs. 2a and b of Oman et al., 2008). In fact, for the purpose of our analysis, it is not crucial that the ERA-I stratospheric water vapour data closely reproduce the observations. What is important is that the ERA-I stratospheric water vapour data have a seasonal cycle and a spatial distribution that indicate it is an adequate tracer for advection associated with DTs and $\left\langle\overline{w^{*}}\right\rangle$. Nevertheless, a recent evaluation of the ERA-I water vapour data against high resolution airborne water vapour data (FISH measurements) suggests that in the upper troposphere (in regions above the subtropical jet stream) and the stratosphere the data sets agree fairly well (A. Kunz, personal communication, 2012). Therefore it is possible that the negative correlations in the right panel of Fig. 11 reflect the effect of the horizontal advection of that minimum and the subsidence of the first tropopause associated with DT events (Añel et al., 2008; Peevey et al., 2012). The left panel of Fig. 11, HALOE-MLS data, shows a stronger reduction in the correlations compared to the right panel of that figure. The difference between DTs correlations with satellite water vapour and with ERA-I data is not necessarily a consequence of the degraded quality of the water vapour in the lower stratosphere from the reanalysis product. Other factors may make the differences reasonable. For example, we are aware that the time and zonal averages of the satellite observations may fail to sample regions where DTs events were identified in the reanalysis, whereas for each DT event there is always a collocated ERA-I water vapour datum.

The correlation signals of DTs and tropical upwelling (the strength of the upward branch of the BDC in the lower stratosphere) can be well separated within the TCO anomalies. Figure 12 shows the lagged correlations of the area weighted average of TCO in the band $30-45^{\circ} \mathrm{N}$ with the DTs $\left(\mathrm{FA}_{\mathrm{NH}}\right)$, with the tropical upwelling $\left(\left\langle\overline{w^{*}}\right\rangle\right)$ and with the residual variability of the DT time series after removing the variabilities linearly regressed upon the tropical upwelling. As in Sect. 3.2, the time series were smoothed by a 3-month moving average. The TCO anomalies associated with $\left\langle\overline{w^{*}}\right\rangle$ should represent a time integrated effect of the anomalies in the residual Lagrangian transport. Therefore the maximum correlation between TCO and $\left\langle\overline{w^{*}}\right\rangle$ anomalies should occur with the tropical upwelling anomalies leading as it is observed in Fig. 12. The correlations between the TCO and the DTs have a maximum at zero lag, consistent with a fast transport by horizontal advection. The correlation at zero lag remains statistically significant above the $99 \%$ level $(p=0.01)$ even after removing the variabilities associated with the tropical upwelling.

Finally, we analyze the step like decrease of water vapour in the lower stratosphere after 2001, which has been reported in the recent literature (e.g., Randel et al., 2006; Randel, 2010). Given the strong correlation between tropical 


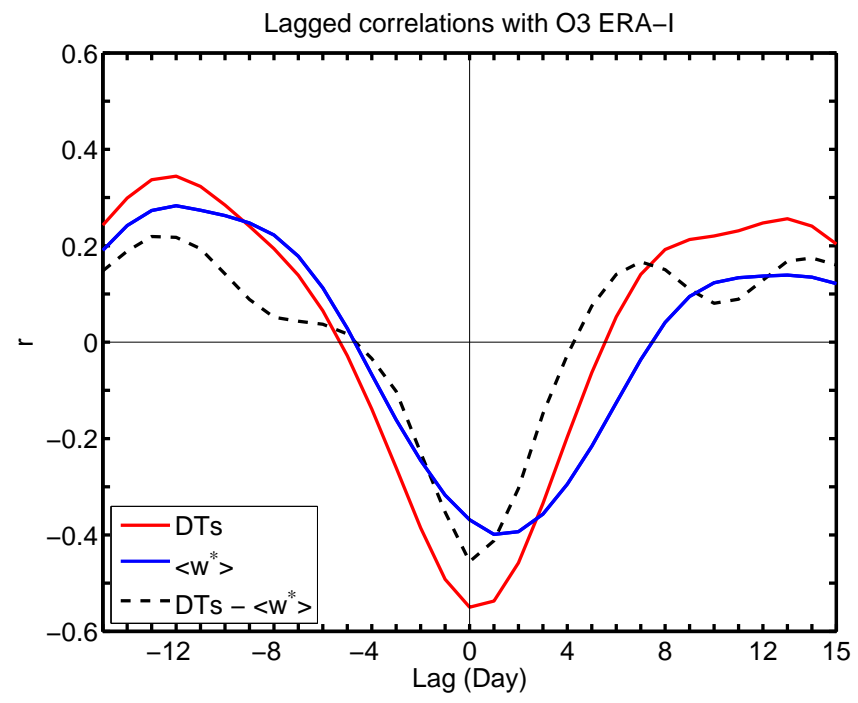

Fig. 12. Lagged correlations of the area averaged TCO in the band $30-45^{\circ} \mathrm{N}$ with the DTs $\left(\mathrm{FA}_{\mathrm{NH}}\right)$ (red), with the tropical upwelling $\left(\left\langle\overline{w^{*}}\right\rangle\right)$ (blue) and with the residual variability of the DT time series after removing the variabilities linearly regressed upon the tropical upwelling (dashed black). The time series were smoothed by a 3month moving average. Negative lags mean that TCO is leading.
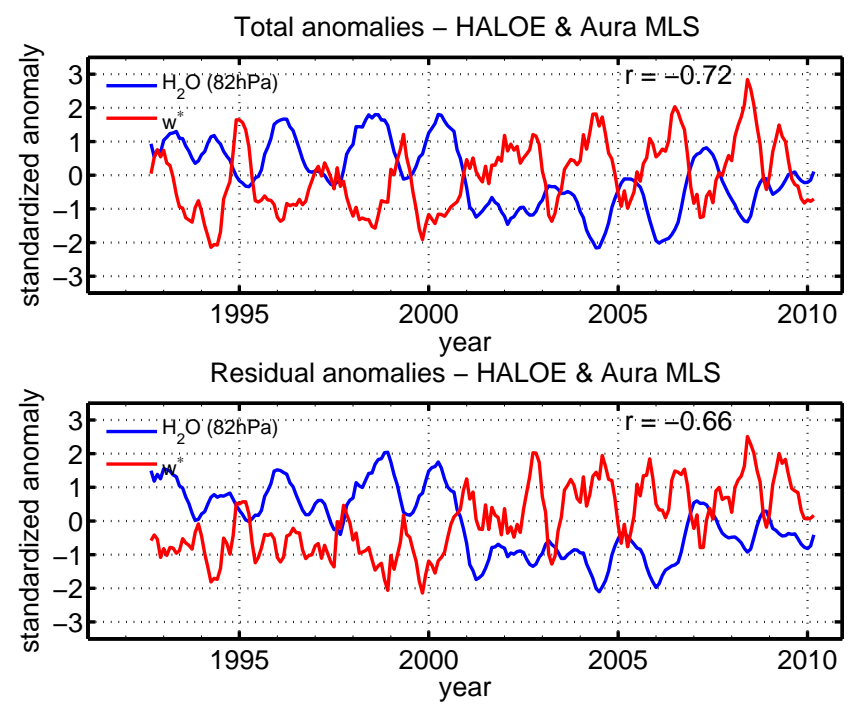

Fig. 13. Time series of mean residual vertical velocity, $\left\langle\bar{w}^{*}\right\rangle$, in the tropics $\left(22.5^{\circ} \mathrm{S}-22.5^{\circ} \mathrm{N}\right)$ and the near-global $\left(50^{\circ} \mathrm{S}-50^{\circ} \mathrm{N}\right)$ water vapour anomalies at $82 \mathrm{hPa}$. Water vapour data were derived from the HALOE and Aura MLS instruments. Both time series were smoothed by a 5-month running mean and normalized by their respective standard deviations. The time series of the residual vertical velocity leads the water vapour by 3 months. This means that the vertical velocity time series was shifted three months to the left in the plot. The bottom panel show the two anomaly time series after the QBO, ENSO and solar cycle signals have been removed from the original anomaly time series by multilinear regressions.

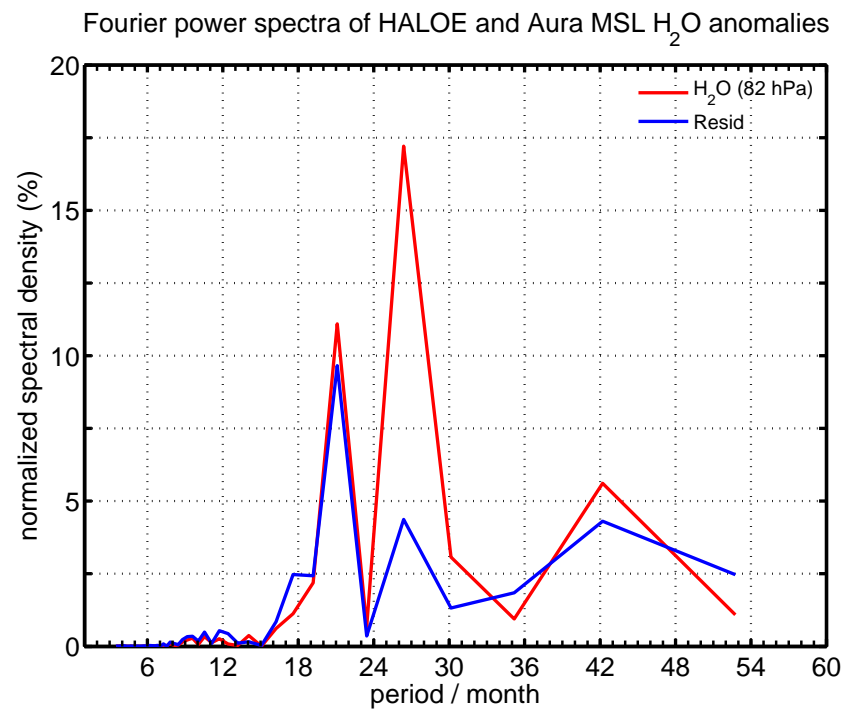

Fig. 14. Fourier power spectra of the water vapour time series shown in Fig. 13 (the HALOE and AURA water vapor anomalies in the lower stratosphere, $82 \mathrm{hPa}$ ). The red curve shows the spectrum of the original time series, and the blue curve shows the spectrum of the residual time series, i.e., the water vapour time series after the QBO, ENSO and solar cycle signals have been removed by a multilinear regression. The spectra were normalized by the total variance of the original time series.

upwelling and water vapour in satellite data, if the observed decrease in stratospheric water vapour after 2001 was due to a change in the transport through the tropical tropopause as argued by Randel et al. (2006) and by Randel (2010), then a clear signal should be also visible in the time series of the tropical upwelling. To see this signal we use the original time series without removing the means before and after 2001. Figure 13 shows an increase in the mean tropical upwelling (upward branch of the BDC) after 2001. Moreover, the lower panel shows that the increase is not covariant with the QBO, the ENSO or the solar cycle. This increase of the mean tropical upwelling is consistent with a higher, colder and drier tropical tropopause leading to a decrease of water vapour in the lower stratosphere (Randel, 2010, Plate 6). Dhomse et al. (2008) had also related the sudden decrease in lower stratospheric water vapour after 2001 with a sudden rise in the strength of the BDC. Those authors used the $50 \mathrm{hPa}$ eddy heat flux averaged from $45^{\circ}$ to $75^{\circ}$ and added from both hemispheres to represent the strength of the BDC.

It is interesting to note that a QBO signal is yet discernible in the residual time series for the water vapour (lower panel of Fig. 13). This indicates that the variability of lower stratosphere water vapour has a nonlinear response to the QBO. In fact, the saturation pressure of water vapour entering in the lower stratosphere is a nonlinear function of the tropopause temperature and, additionally, the water vapour anomalies do not vary linearly with the tropopause temperature anomalies 
associated with the QBO. Although a QBO signal seems discernible in the residual time series of water vapor shown in the lower panel of Fig. 13, a Fourier spectral analysis (Fig. 14) revealed that the fraction of variance associated with the QBO period has been strongly reduced by the subtraction of the linear signal of the QBO. Moreover, a similar spectral analysis applied to the time series anomalies of the ERA-I water vapour, DTs, and tropical upwelling revealed also a stronger reduction in the fraction of variance associated with the QBO period in the residuals of those time series (see Appendix A). In the Appendix we also discuss the ENSO signal in the water vapour.

\section{Concluding remarks}

This study presents a statistical analysis of relationships between the upward branch of the BDC (tropical upwelling), the area covered by DTs, stratospheric ozone and lower stratospheric water vapour. The influence of the QBO and the ENSO signals on these relationships was also assessed. A clear signal of the QBO and the ENSO within the frequency of DTs is demonstrated. The existence of a strong correlation between the strength of the upward branch of the BDC, as determined by the downward control principle, and the area of DTs was also demonstrated. The findings of Castanheira and Gimeno (2011) and Peevey et al. (2012) suggesting an association between DTs and Rossby waves were also demonstrated here by the positive correlation between the DTs and the area weighted average of the quasi-geostrophic wave activity in the latitudinal band $30-50^{\circ} \mathrm{N}$. In fact, because both the BDC and DTs are associated with wave activity in subtropics, the existence of a relationship between them could be anticipated.

Negative correlations between the area covered by DTs and the TCO or the lower stratospheric water vapour may be understood as a consequence of the poleward displacement of tropical air within the upper troposphere/lower stratosphere (UTLS) region that occurs during a DT event. This is likely the case because the lower most tropical stratosphere is drier and has a smaller ozone mixing ratio; therefore, the poleward displacement of tropical UTLS air will produce negative anomalies in the lower stratospheric water vapour and TCO at midlatitudes. The anomalies in the water vapour may also be partially attributed to an observed subsidence of the first lapse rate tropopause associated with DTs events. Additionally, the poleward motion of tropical UTLS air with the tropical tropopause overlying the extratropical one must be accompanied by an increase in the frequency of tropospheric intrusions into the lower extratropical stratosphere. This is confirmed by the positive correlation between DTs and ozone laminae found in the HIRDLS data.

The above results were based on the analysis of both instrumental data and ERA-I reanalysis data. Results from these two types of datasets are consistent, with the main dif- ference being the stronger BDC in the ERA-I reanalysis that has already been reported by Dee et al. (2011).

The significant anticorrelation between the tropical upwelling and the near global lower stratospheric water vapour is consistent with an uplift of the tropical tropopause accompanying a strengthening of the upward branch of the BDC. A higher tropopause will be colder and drier, leading to negative anomalies in the input of water vapour into the stratosphere. The results are consistent with the findings of Randel et al. (2006) and Randel (2010) which suggest that the decrease in the stratospheric water vapour after 2001 is linked to changes in the tropical tropopause and the Brewer-Dobson circulation. In fact, the results here show that the step like decrease in the lower stratospheric water vapour after 2001 is mirrored by a step like increase in the tropical upwelling.

As a final note, we remark that our analysis revealed that DTs are an important factor in the variability of stratospheric ozone and lower stratospheric water vapour, both important species for Earth's climate. Moreover, this study shows that the variability in DT events is associated with the variability of the upward branch of BDC at the tropical tropopause level through Rossby wave dynamics, adding to the current understanding of the mechanisms responsible for DT formation.

\section{Appendix A}

\section{Fourier power spectra}

The Fourier power spectra of the detrended time series anomalies of the ERA-I water vapour, DTs, and tropical upwelling used in Figs. 7, 8, 10 and 11 are shown in Figs. A1, $\mathrm{A} 2$ and $\mathrm{A} 3$. The time series were previously detrended by subtracting a 10-yr (121 months) running average. In order to make the spectra comparable, the spectra were normalized by the variance of the original detrended time series, i.e., both the spectra of the original detrended time series and residual detrended time series were presented as fractions of the variance of the original detrended time series.

All residual time series in the previous sections were calculated with no lag for the ENSO time series. This seems adequate when examining the fraction of area covered with DTs (FA) and the tropical upwelling $\left(\left\langle\overline{\left.w^{*}\right\rangle}\right\rangle\right.$. In fact, the residual spectra of FA and $\left\langle\overline{w^{*}}\right\rangle$ have amplitudes smaller than that of the original spectra for periods around four years (48 months). The opposite is observed for the residual spectrum of the ERA-I water vapour (the blue curve in Fig. A1). However after calculating the residual time series of the ERA-I water vapour anomalies with the ENSO index leading by six months the Fourier spectrum (the green curve in Fig. A1) has amplitudes smaller than that of the original spectrum for periods around four years (48 months). This behaviour may be understood if we take into consideration that we are using near global $\left(50^{\circ} \mathrm{S}-50^{\circ} \mathrm{N}\right)$ isobaric averages of the water vapour mixing ratios, and that there is a lag between the 


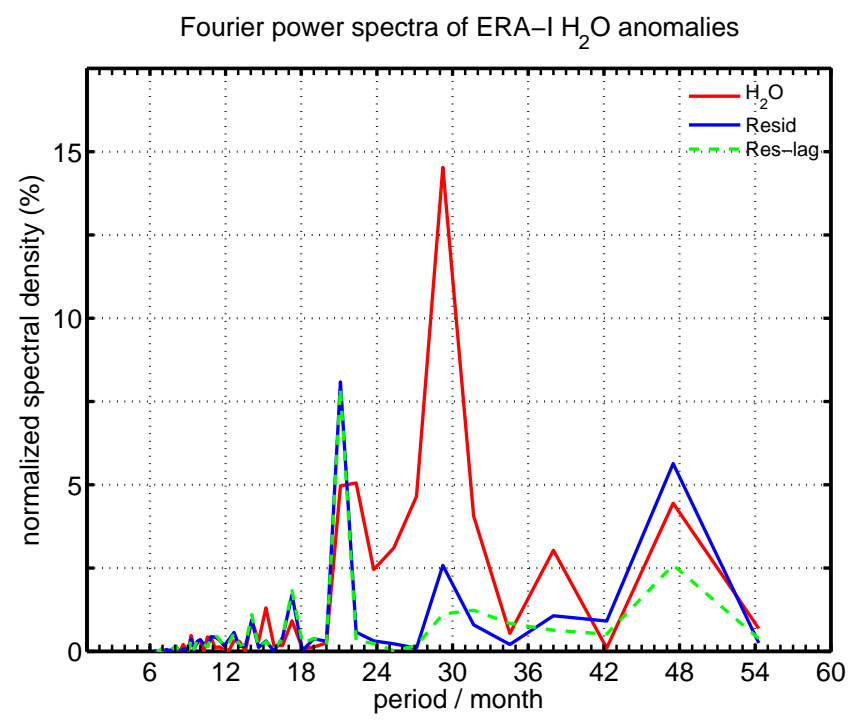

Fig. A1. Fourier power spectra of the detrended time series anomalies of the mean specific humidity of ERA-I at the 100 - and $70 \mathrm{hPa}$ levels. We computed the mean of these two levels to have a more direct comparison with the spectra shown in Fig. 14, which were computed for satellite water vapour data at $82 \mathrm{hPa}$. The blue curve shows the spectrum of the residual time series, i.e., the water vapour time series after the QBO, ENSO and solar cycle signals have been removed by a multilinear regression. The dashed green curve represents the spectrum of the residual time series of the ERA-I water vapour anomalies calculated with the ENSO index leading by six months. The spectra were normalized by the total variance of the original detrended time series.

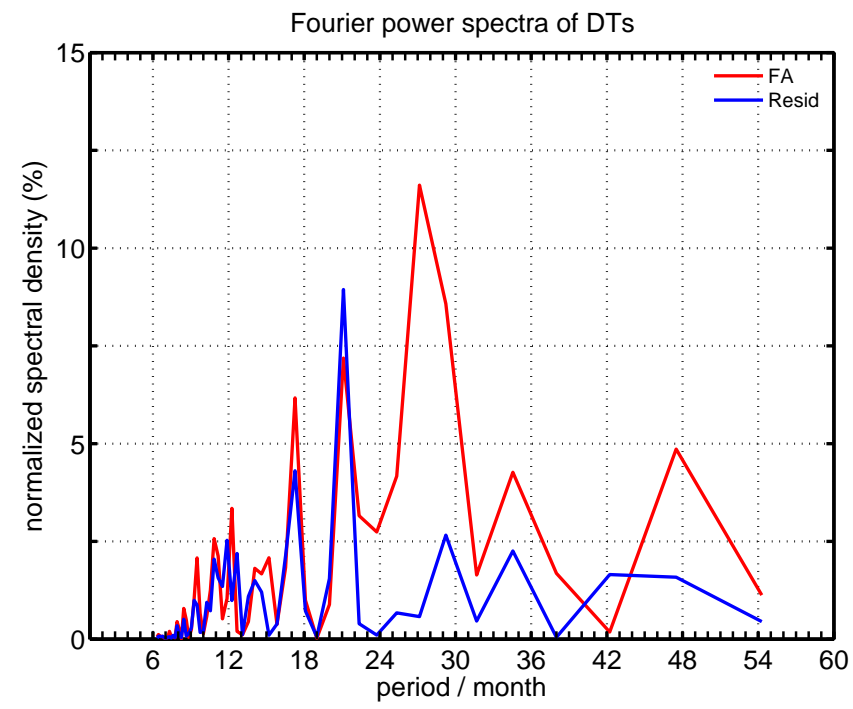

Fig. A2. Fourier power spectra of the detrended time series anomalies of fraction of area covered with DTs, FA. The blue curve shows the spectra of the residual time series, i.e., the FA time series after the QBO, ENSO and solar cycle signals have been removed by a multilinear regression.

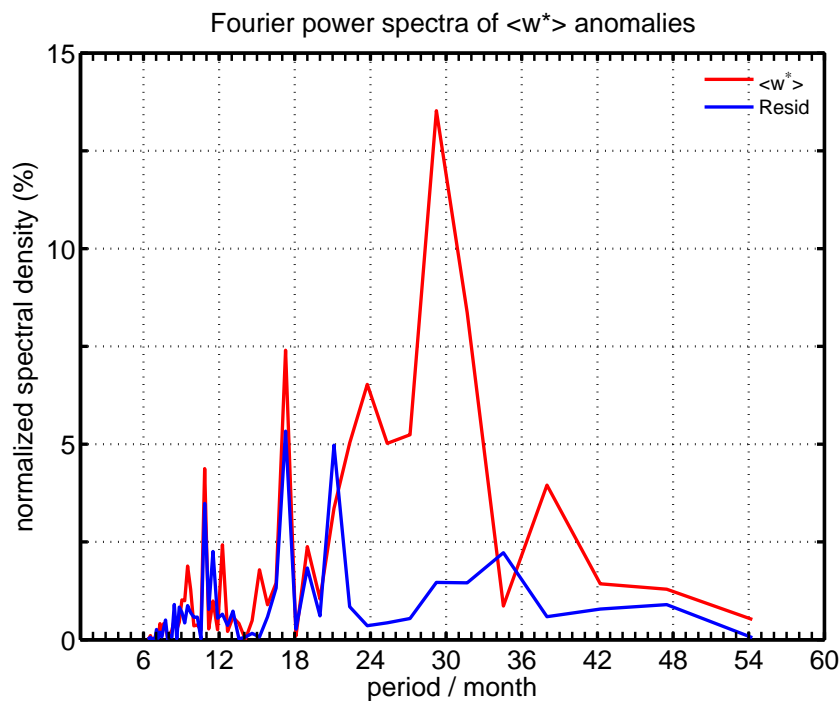

Fig. A3. As in Fig. A2 but for the tropical upwelling.

anomalous input of water vapour in the tropical stratosphere and the propagation of the anomalies to extratropical latitudes. A more detailed investigation of the lags between the ENSO index and the water vapour time series will be considered in a future analysis. In such analysis we must take into account the fact that the lag would likely be different for different isobaric levels, and that it may be useful to analyse over shorter latitudinal bands.

Acknowledgements. We would like to thank William Randel for making water vapour data from the HALOE and Aura MLS available to us. We would like also to thank John Gille, Bruno Nardi and the HIRDLS Team for their efforts in maintaining and continually improving the HIRDLS temperature and ozone data.

This work was partially supported by the DYNOZONE project (PTDC/CTE-ATM/105507/2008) funded by the FCT (Fundação para a Ciência e a Tecnologia, Portugal).

Edited by: F. Fierli

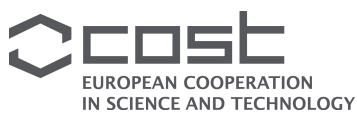

This publication is supported by COST - www.cost.eu

\section{References}

Andrews, D. G., Holton, J. R., and Leovy, C. B.: Middle Atmosphere Dynamics, Academic Press, UK, 489 pp., 1987.

Añel, J. A., Antuña, J. C., de la Torre, L., Castanheira, J. M., and Gimeno, L.: Climatological features of global multiple tropopause events, J. Geophys. Res., 113, D00B08, doi:10.1029/2007JD009697, 2008.

Baldwin, M. P., Gray, L. G, Dunkerton, T. J., Hamilton, K., Haynes, P. H., Randel, W. J., Holton, J. R., Alexander, M. J., Hirota, I., Horinouchi, T., Jones, D. B. A., Kinnersley, J. S., Marquardt, 
C., Sato, K., and Takahashi, M.: The Quasi-Biennial Oscillation, Rev. Geophys., 39, 179-230, 2001.

Birner, T.: Recent widening of the tropical belt from global tropopause statistics: sensitivities, J. Geophys. Res., 115, D23109, doi:10.1029/2010JD014664, 2010.

Bönisch, H., Engel, A., Birner, Th., Hoor, P., Tarasick, D. W., and Ray, E. A.: On the structural changes in the Brewer-Dobson circulation after 2000, Atmos. Chem. Phys., 11, 3937-3948, doi:10.5194/acp-11-3937-2011, 2011.

Castanheira, J. M. and Gimeno, L.: Association of double tropopause events with baroclinic waves, J. Geophys. Res., 116, D19113, doi:10.1029/2011JD016163, 2011.

Dee, D. P., Uppala, S. M., Simmons, A. J., Berrisford, P., Poli, P., Kobayashi, S., Andrae, U., Balmaseda, M. A., Balsamo, G., Bauer, P., Bechtold, P., Beljaars, A. C. M., van de Berg, L., Bidlot, J., Bormann, N., Delsol, C., Dragani, R., Fuentes, M., Geer, A. J., Haimberger, L., Healy, S. B., Hersbach, H., Hólm, E. V., Isaksen, L., Kållberg, P., Köhler, M., Matricardi, M., McNally, A. P., Monge-Sanz, B. M., Morcrette, J.-J., Park, B.-K., Peubey, C., de Rosnay, P., Tavolato, C., Thépaut, J.-N., and Vtart, F.: The ERA-Interim reanalysis: configuration and performance of the data assimilation system, Q. J. Roy. Meteorol. Soc., 137, 553597, doi:10.1002/qj.828, 2011.

Dhomse, S., Weber, M., and Burrows, J.: The relationship between tropospheric wave forcing and tropical lower stratospheric water vapor, Atmos. Chem. Phys., 8, 471-480, doi:10.5194/acp-8-4712008, 2008.

Dragani, R.: On the quality of the ERA-Interim ozone reanalyses: comparisons with satellite data, Q. J. Roy. Meteorol. Soc., 137, 1312-1326, doi:10.1002/qj.821, 2011.

Gille, J. C. and Gray, L. J.: High Resolution Dynamics Limb Sounder Earth Observing System (EOS) data description and quality version 5, report, 63 pp., Dep. of Atmos. Oceanic and Planet. Phys., Oxford Univ., Oxford, UK, available at: http://www.eos.ucar.edu/hirdls/data/products/ HIRDLS-V5-DQD.pdf, 2010.

Fujiwara, M., Vomel, H., Hasebe, F., Shiotani, M., Ogino, S.Y, Iwasaki, S., Nishi, N., Shibata, T., Shimizu, K., Nishimoto, E., Valverde Canossa, J. M., Selkirk, H. B., and Oltmans, S. J.: Seasonal to decadal variations of water vapor in the tropical lower stratosphere observed with balloon-borne cryogenic frost point hygrometers, J. Geophys. Res., 115, D18304, doi:10.1029/2010JD014179, 2010.

Holton, J. R., Haynes, P. H., McIntyre, M. E., Douglass, A. R., Rood, R. B., and Pfister, L.: Stratosphere-Troposphere Exchange, Rev. Geophys., 33, 403-439, 1995.

Homeyer, C. R., Bowman, K. P., Pan, L. L., Atlas, E. L., Gao, R., and Campos, T. L.: Dynamical and Chemical Characteristics of Tropospheric Intrusions Observed during START08, J. Geophys. Res., 116, D06111, doi:10.1029/2010JD015098, 2011.

Huang, F. T., Mayr, H. G., Reber, C. A., Russell III, J. M., Mlynczak, M. G., and Mengel, J. G.: Ozone quasi-biennial oscillations (QBO), semiannual oscillations (SAO), and correlations with temperature in the mesosphere, lower thermosphere, and stratosphere, based on measurements from SABER on TIMED and MLS on UARS, J. Geophys. Res., 113, A01316, doi:10.1029/2007JA012634, 2008.

Le Texier, H., Solomon, S., and Garcia, R. R.: The role of molecular hydrogen and methane oxidation in the water vapour budget of the stratosphere, Q. J. Roy. Meteorol. Soc., 114, 281-295, 1988.

McFarlane, N.: Connections between stratospheric ozone and climate: radiative forcing, climate variability, and change, Atmos. Ocean, 46, 139-158, 2008.

Mote, P. W., Rosenlof, K. H., McIntyre, M. E., Carr, E. S., Gille, J. C., Holton, J. R., Kinnersley, J. S., Pumphrey, H. C., Russell, J. M., and Waters, J. W.: An atmospheric tape recorder: the imprint of tropical tropopause temperatures on stratospheric water vapour, J. Geophys. Res., 101, 3989-4006, 1996.

Olsen, M. A., Douglass, A. R., Schoeberl, M. R., Rodriquez, J. M., and Yoshida, Y.: Interannual variability of ozone in the winter lower stratosphere and the relationship to lamina and irreversible transport, J. Geophys. Res., 115, D15305, doi:10.1029/2009JD013004, 2010.

Oman, L., Waugh, D. W., Pawson, S., Stolarski, R. S., Nielsen, J. E.: Understanding the Changes of Stratospheric Water Vapor in Coupled Chemistry-Climate Model Simulations, J. Atmos. Sci., 65, 3278-3291, doi:10.1175/2008JAS2696.1, 2008.

Pan, L. L., Randel, W. J., Gille, J. C., Hall, W. D., Nardi, B., Massie, S., Yudin, V., Khosravi, R., Konopka, P., and Tarasick, D.: Tropospheric intrusions associated with the secondary tropopause, J. Geophys. Res., 114, D10302, doi:10.1029/2008JD011374, 2009.

Peevey, T. R., Gille, J. C., Randall, C. E., and A. Kunz: Investigation of double tropopause spatial and temporal global variability utilizing High Resolution Dynamics Limb Sounder temperature observations, J. Geophys. Res., 117, D01105, doi:10.1029/2011JD016443, 2012.

Randel, W. J.: Variability and trends in stratospheric temperature and water vapour, in: The Stratosphere: Dynamics, Transport and Chemistry, Geophys. Monogr. Ser. 190, AGU, Polvani, edited by: Polvani, L. M., Sobel A. H., and Waugh, D. W., 123-135, doi:10.1029/2009GM000870, Washington, USA, 2010.

Randel, W. J., Wu, F., Russell III, J. M., Roche, A., and Waters, J. W.: Seasonal cycles and QBO variations in stratospheric $\mathrm{CH}_{4}$ and $\mathrm{H}_{2} \mathrm{O}$ observed in UARS HALOE data, J. Atmos. Sci., 55, 163-185, 1998.

Randel, W. J., Garcia, R. R., and Wu, F.: Time-dependent upwelling in the tropical lower stratosphere estimated from the zonal-mean momentum budget, J. Atmos. Sci., 59, 2141-2152, 2002.

Randel, W. J., Wu, F., Vomel, H., Nedoluha, G. E., and Forster, P.: Decreases in stratospheric water vapor after 2001: Links to changes in the tropical tropopause and the Brewer-Dobson circulation, J. Geophys. Res., 111, D12312, doi:10.1029/2005JD006744, 2006.

Randel, W. J., Seidel, D. J., and Pan, L. L.: Observational characteristics of double tropopauses, J. Geophys. Res., 112, D07309, doi:10.1029/2006JD007904, 2007.

Reichler, T., Dameris, M., and Sausen, R.: Determining the tropopause height from gridded data, Geophys. Res. Lett., 30, 2042, doi:10.1029/2003GL018240, 2003.

Roff, G., Thompson, D. W. J., and Hendon, H.: Does increasing model stratospheric resolution improve extended range forecast skill?, Geophys. Res. Lett., 38, L05809, doi:10.1029/2010GL046515, 2011.

Schoeberl, M. R., Douglass, A. R., Stolarski, R. S., Pawson, S., Strahan, S. E., and Read, W.: Comparison of lower stratospheric tropical mean vertical velocities, J. Geophys. Res., 113, D24109, doi:10.1029/2008JD010221, 2008. 
Sigmond, M., Scinocca, J. F., and Kushner, P. J.: Impact of the stratosphere on tropospheric climate change, Geophys. Res. Lett., 35, L12706, doi:10.1029/2008GL033573, 2008.

Solomon, S., Rosenlof, K. H., Portmann, R. W., Daniel, J. S., Davis, S. M., Sanford, T. J., and Plattner, G. K.: Contributions of Stratospheric Water Vapor to Decadal Changes in the Rate of Global Warming, Science, 327, 1219-1223, doi:10.1126/science.1182488, 2010.
Staehelin, J. N., Harris, R. P., Appenzeller, C., and Eberhard, J.: Ozone trends: A review, Rev. Geophys., 39, 231-290, doi:10.1029/1999RG000059, 2001

World Meteorological Organization: Meteorology: A threedimensional science, WMO Bull., 6, 134-138, 1957. 